\title{
Ethical Guidelines for Counseling Supervisors
}

By: Gordon Hart, L. DiAnne Borders, Don Nance, Louis Paradise

This is the pre-peer reviewed version of the following article: Hart, G., Borders, L. D., Nance, D., \& Paradise, L. (1995). Ethical guidelines for counseling supervisors. Counselor Education and Supervision, 34(3), 270-276., which has been published in final form at http://onlinelibrary.wiley.com/doi/10.1002/j.1556-6978.1995.tb00248.x/abstract.

\begin{abstract}
:
The following Ethical Guidelines for Counseling Supervisors were adopted by the Association for Counselor Education and Supervision (ACES) Governing Council in March of 1993. The guidelines were written by a subcommittee of the ACES Supervision Interest Group, which comprised the following members: Gordon Hart, Chair; L. DiAnne Borders; Don Nance; and Louis Paradise. The guidelines first appeared in ACES Spectrum, Volume 53, Number 4, Summer, 1993.
\end{abstract}

Keywords: Counseling | Supervisors | Ethics

Article:

The following Ethical Guidelines for Counseling Supervisors were adopted by the Association for Counselor Education and Supervision (ACES) Governing Council in March of 1993. The guidelines were written by a subcommittee of the ACES Supervision Interest Group, which comprised the following members: Gordon Hart, Chair; L. DiAnne Borders; Don Nance; and Louis Paradise. The guidelines first appeared in ACES Spectrum, Volume 53, Number 4, Summer, 1993.

\section{PREAMBLE}

The Association for Counselor Education and Supervision (ACES) is composed of people engaged in the professional preparation of counselors and people responsible for the ongoing supervision of counselors. ACES is a founding division of the American Counseling Association (ACA) and, as such, adheres to ACA's current Ethical Standards (ACA, 1988) and to general codes of competence adopted throughout the mental health community.

ACES believes that counselor educators and counseling supervisors in universities and in applied counseling settings, including the range of education and mental health delivery systems, carry responsibilities unique to their Job roles. Such responsibilities may include administrative supervision, clinical supervision, or both. Administrative supervision refers to those supervisory activities that increase the efficiency of the delivery of counseling services, whereas clinical supervision includes the supportive and educative activities of the supervisor designed to improve the application of counseling theory and technique directly to clients. 
Counselor educators and counseling supervisors encounter situations that challenge the help given by general ethical standards of the profession at large. These situations require more specific guidelines that provide appropriate guidance in everyday practice.

The Ethical Guidelines for Counseling Supervisors are intended to assist professionals by helping them:

1. Observe ethical and legal protection of clients' and supervisees' rights;

2. Meet the training and professional development needs of supervisees in ways consistent with clients' welfare and programmatic requirements; and

3. Establish policies, procedures, and standards for implementing programs.

The specification of ethical guidelines enables ACES members to focus on and to clarify the ethical nature of responsibilities held in common. Such guidelines should be reviewed formally every 5 years, or more often if needed, to meet the needs of ACES members for guidance.

The Ethical Guidelines for Counselor Educators and Counseling Supervisors are meant to help ACES members in conducting supervision. ACES is not currently in a position to hear complaints about alleged noncompliance with these guidelines. Any complaints about the ethical behavior of any ACA member should be measured against the ACA Ethical Standards and a complaint lodged with ACA in accordance with their procedures for doing so.

One overriding assumption underlying this document is that supervision should be ongoing throughout a counselor's career and should not stop when a particular level of education, certification, or membership in a professional organization is attained.

\section{Definitions of Terms}

Applied Counseling Settings--Public or private organizations of counselors such as community mental health centers, hospitals, schools, and group or individual private practice settings.

Supervisees--Counselors-in-training in university programs at any level who are working with clients in applied settings as part of their university training program, and counselors who have completed their formal education and are employed in an applied counseling setting.

Supervisors--Counselors who have been designated within their university or agency to directly oversee the professional clinical work of counselors. Supervisors also may be persons who offer supervision to counselors seeking state licensure and so provide supervision outside of the administrative aegis of an applied counseling setting.

\section{Client Welfare and Rights}


- 1.01 The primary obligation of supervisors is to train counselors so that they respect the integrity and promote the welfare of their clients. Supervisors should have supervisees inform clients that they are being supervised and that observation or recordings of the session may be reviewed by the supervisor.

- 1.02 Supervisors who are licensed counselors and are conducting supervision to aid a supervisee to become licensed should instruct the supervisee not to communicate or in any way convey to the supervisee's clients or to other parties that the supervisee is himself or herself licensed.

- 1.03 Supervisors should make supervisees aware of clients' rights, including protecting clients' right to privacy and confidentiality in the counseling relationship and the information resulting from it. Clients also should be informed that their right to privacy and confidentiality will not be violated by the supervisory relationship.

- 1.04 Records of the counseling relationship, including interview notes, test data, correspondence, the electronic storage of these documents, and audio- and videotape recordings are considered to be confidential professional information. Supervisors should see that these materials are used in counseling, research, and training and supervision of counselors with the full knowledge of the client and that permission to use these materials is granted by the applied counseling setting offering service to the client. This professional information is to be used for the full protection of the client. Written consent from the client (or legal guardian, if a minor) should be secured prior to the use of such information for instructional, supervisory, or research purposes. Policies of the applied counseling setting regarding client records also should be followed.

- 1.05 Supervisors shall adhere to current professional and legal guidelines when conducting research with human beings such as Section D-1 of the ACA Ethical Standards.

- 1.06 Counseling supervisors are responsible for making every effort to monitor both the professional actions, and failures to take action, of their supervisees.

\section{Supervisory Role}

Inherent and integral to the role of supervisor are responsibilities for:

a. Monitoring client welfare;

b. Encouraging compliance with relevant legal, ethical, and professional standards for clinical practice;

c. Monitoring clinical performance and professional development of supervisees; and 
d. Evaluating and certifying current performance and potential of supervisees for academic, screening, selection, placement, employment, and credentialing purposes.

- 2.01 Supervisors should have had training in supervision prior to initiating their role as supervisors.

- $\quad$ 2.02 Supervisors should pursue professional and personal continuing education activities such as advanced courses, seminars, and professional conferences on a regular and ongoing basis. These activities should include both counseling and supervision topics and skills.

- $\quad 2.03$ Supervisors should make their supervisees aware of professional and ethical standards and legal responsibilities of the counseling profession.

- $\quad$ 2.04 Supervisors of postdegree counselors who are seeking state licensure should encourage these counselors to adhere to the standards for practice established by the state licensure board of the state in which they practice.

- $\quad$ 2.05 Procedures for contacting the supervisor, or an alternative supervisor, to assist in handling crisis situations should be established and communicated to supervisees.

- $\quad 2.06$ Actual work samples via audio- or videotape or live observation in addition to case notes should be reviewed by the supervisor as a regular part of the ongoing supervisory process.

- $\quad$ 2.07 Supervisors of counselors should meet regularly in face-to-face sessions with their supervisees.

- $\quad 2.08$ Supervisors should provide supervisees with ongoing feedback on their performance. This feedback should take a variety of forms, both formal and informal, and should include verbal and written evaluations. It should be formative during the supervisory experience and summative at the conclusion of the experience.

- $\quad$ 2.09 Supervisors who have multiple roles (e.g., teacher, clinical supervisor, administrative supervisor) with supervisees should minImize potential conflicts. When possible, the roles should be divided among several supervisors. When this is not possible, careful explanation should be conveyed to the supervisee as to the expectations and responsibilities associated with each supervisory role.

- $\quad$ 2.10 Supervisors should not participate in any form of sexual contact with supervisees. Supervisors should not engage in any form of social contact or interaction that would compromise the super-visor-supervisee relationship. Dual relationships with supervisees that might impair the supervisor's objectivity and professional judgment should be avoided or the supervisory relationship terminated. 
- 2.11 Supervisors should not establish a psychotherapeutic relationship as a substitute for supervision. Personal issues should be addressed in supervision only in terms of the effect of these issues on clients and on professional functioning.

- 2.12 Supervisors, through ongoing supervisee assessment and evaluation, should be aware of any personal or professional limitations of supervisees that are likely to impede future professional performance. Supervisors have the responsibility of recommending remedial assistance to the supervisee and of screening from the trainIng program, applied counseling setting, or state licensure those supervisees who are unable to provide competent professional services. These recommendations should be clearly and professionally explained in writing to the supervisees who are so evaluated.

- 2.13 Supervisors should not endorse a supervisee for certification, licensure, completion of an academic training program, or continued employment if the supervisor believes the supervisee is impaired in any way that would interfere with the performance of counseling duties. The presence of any such impairment should begin a process of feedback and remediation wherever possible so that the supervisee understands the nature of the impairment and has the opportunity to remedy the problem and continue with his or her professional development.

- 2.14 Supervisors should incorporate the principles of informed consent and participation; clarity of requirements, expectations, roles and rules; and due process and appeal into the establishment of policies and procedures of their institution, program, courses, and individual supervisory relationships. Mechanisms for due process appeal of individual supervisory actions should be established and made available to all supervisees.

\section{Program Administration Role}

- 3.01 Supervisors should ensure that the programs conducted and experiences provided are in keeping with current guidelines and standards of ACA and its divisions.

- 3.02 Supervisors should teach courses or supervise clinical work only in areas in which they are fully competent and experienced.

- $\quad 3.03$ To achieve the highest quality of training and supervision, supervisors should be active participants in peer review and peer supervision procedures.

- 3.04 Supervisors should provide experiences that integrate theoretical knowledge and practical application. Supervisors also should provide opportunities in which supervisees are able to apply the knowledge they have learned and understand the rationale for the skills they have acquired. The knowledge and skills conveyed should reflect current practice, research findings, and available resources. 
- 3.05 Professional competencies, specific courses, or required experiences expected of supervisees should be communicated to them in writing prior to admission to the training program, placement, or employment by the applied counseling setting, and, in the case of continued employment, in a timely manner.

- 3.06 Supervisors should accept only those persons as supervisees who meet identified entry-level requirements for admission to a program of counselor training or for placement in an applied counseling setting. In the case of private supervision in search of state licensure, supervisees should have completed all necessary prerequisites as determined by the state licensure board.

- 3.07 Supervisors should inform supervisees of the goals, policies, theoretical orientations toward counseling, training, and supervision model or approach In which the supervision is based.

- 3.08 Supervisees should be encouraged and assisted to define their own theoretical orientation toward counseling, to establish supervision goals for themselves, and to monitor and evaluate their progress toward meeting these goals.

- 3.09 Supervisors should assess supervisees' skills and experience to establish standards for competent professional behavior. Supervisors should restrict supervisees' activities to those that are commensurate with their current level of skills and experiences.

- 3.10 Supervisors should obtain practicum and fieldwork sites that meet minimum standards for preparing students to become effective counselors. No practicum or fieldwork setting should be approved unless it truly replicates a counselIng work setting.

- $\quad 3.11$ Practicum and fieldwork classes should be limited in size according to established professional standards to ensure that each student has ample opportunity for individual supervision and feedback. Supervisors in applied counseling settings should have a limited number of supervisees.

- 3.12 Supervisors In university settings should establish and communicate specific policies and procedures regarding field placement of students. The respective rules of the student counselor, the university supervisor, and the field supervisor should be dearly differentiated in areas such as evaluation, requirements, and confidentiality.

- 3.13 Supervisors In training programs should communicate regularly with supervisors in agencies used as practicum or fieldwork sites regarding current professional practices, expectations of students, and preferred models and modalities of supervision.

- 3.14 Supervisors at the university should establish clear lines of communication among themselves, the field supervisors, and the students or supervisees. 
- 3.15 Supervisors should establish and communicate to supervisees and to field supervisors specific procedures regarding consultation, performance review, and evaluation of supervisees.

- 3.16 Evaluations of supervisee performance in universities and in applied counseling settIngs should be available to supervisees in ways consistent with the Family Rights and Privacy Act.

- $\quad 3.17$ Forms of training that focus primarily on self-understanding and problem resolution (e.g., personal growth groups or individual counseling) should be voluntary. Those who conduct these forms of training should not serve simultaneously as supervisors of the supervisees involved in the training.

- 3.18 A supervisor may recommend participation in activities such as personal growth groups or personal counseling when it has been determined that a supervisee has deficits in the areas of self-understanding and problem resolution that impede his or her professional functioning. The supervisor should not be the direct provider of these activities for the supervisee.

- 3.19 When a training program conducts a personal growth or counseling experience involving relatively intimate self-disclosure, care should be taken to eliminate or minimize potential role conflicts for faculty or agency supervisors who may conduct these experiences and who also serve as teachers, group leaders, and clinical directors.

- 3.20 Supervisors should use the following prioritized sequence in resolving conflicts among the needs of the client, the needs of the supervisee, and the needs of the program or agency. Insofar as the client must be protected, it should be understood that client welfare is usually subsumed in federal and state laws such that these statutes should be the first point of reference. When laws and ethical standards are not present or are unclear, the good judgment of the supervisor should be guided by the following list:

a. Relevant legal and ethical standards (e.g., duty to warn, state child abuse laws, etc.);

b. Client welfare;

c. Supervisee welfare;

d. Supervisor welfare; and

e. Program or agency service and administrative needs.

\section{REFERENCE}

American Counseling Association. (1988). Ethical standards (3rd revision). Journal of Counseling and Development, 67, 4-8. 